\title{
Update from RCP Quality Improvement and Patient Safety: Introduction of a new short format for quality improvement reports
}

DOI: 10.7861/fhj.QI.8.1

'QIP' (quality improvement project) has become common parlance among doctors in training and many others. This is largely because there are requirements for foundation trainees and specialty trainees to learn quality improvement practice. The General Medical Council's Generic professional capabilities framework includes 'design and implement quality improvement projects.' There are variable opportunities for doctors in training to develop their quality improvement practice in the UK, and variable levels of support. This leads to some excellent learning and development, but also some doctors 'doing a QIP' without a full understanding of some of the core elements of improvement practice. There is accessible advice available for doctors in training, other professionals and educational supervisors. ${ }^{2-5}$

We have observed common faults in improvement projects from doctors in training which include:

> jumping to solutions without diagnosing the problem

> doing a project alone or without forming the appropriate improvement team

> taking on too much, rather than breaking the problem down into manageable projects

> starting to implement changes before having measures in place to demonstrate benefit or adverse consequences

$>$ only doing before and after measures rather than repeated measures over time

> missing the opportunity to get organisational support through choosing topics that are not part of local priorities

$>$ not involving patients or measuring patient experience

$>$ not capturing learning from what hasn't worked as well as what has

> not doing rapid cycle testing and adapting the interventions.

Presenting and publishing quality improvement projects can consolidate learning for the individuals involved, and importantly disseminate learning for all. There are many forums in which quality improvement projects can be shared in poster or oral presentations, this includes hospital or training programme meetings, regional trainee or Royal College of Physicians (RCP) events, and national specialist or safety and quality improvement conferences. The RCP in collaboration with Health Education England holds regional showcase events for internal medicine trainees (IMTs) to present projects. The winners participate in a national IMT QI showcase, which now is part of the RCP annual Medicine conference. Options for publishing in peer reviewed journals is more limited, often because the projects are circumscribed, learning may be difficult to generalise or the format for the publication does not fit these type of smaller pieces of improvement practice and learning. International guidance on what to include in quality improvement reports is clear through the SQUIRE 2.0 guidance. $^{6}$

Future Healthcare Journal is now offering a short quality improvement reports format, specifically targeted at doctors in training and other professionals to help them report their learning and support others to do similar work. Key elements of these reports also guide those delivering quality improvement to include the important elements in their projects. In particular, this includes the trigger for the project, what is already known from elsewhere, the local context, what was done, what was learned, why this might be important to others and how it might be sustained or spread if successful. More detailed guidance for authors is given at www.rcpjournals.org/content/future-healthcare-journal-

instructions-authors. The peer review process will also guide authors on how to improve the reports before publication.

We look forward to seeing many projects reported in this format, and sharing them online through the $\mathrm{FH}$ ] website.

John Dean

Clinical director of quality improvement and patient safety, Royal College of Physicians

Chris Subbe

Consultant in acute medicine and intensive care and Health Foundation Improvement Fellow,

Betsi Cadwaladr University Health Board

\section{References}

1 General Medical Council. Generic professional capabilities framework. Manchester: GMC, 2017.

2 Swanwick T, Vaux E (eds). ABC of quality improvement in healthcare. London: Wiley, 2020.

3 Royal College of Physicians. Supervising quality improvement projects: A guide for supervisors. London: RCP. www.rcplondon.ac.uk/ education-practice/courses/supervising-quality-improvementprojects-guide-supervisors [Accessed 3 March 2021].

4 NHS England. The Improvement Hub. NHS. www.england.nhs.uk/ improvement-hub [Accessed 3 March 2021].

5 Institute for Healthcare Improvement. IHI Open School. IHI. www. ihi.org/education/IHIOpenSchool/Pages/default.aspx [Accessed 3 March 2021].

6 SQUIRE. Revised Standards for Quality Improvement Reporting Excellence: SQUIRE 2.0. SQUIRE. http://squire-statement.org/index. $\mathrm{cfm}$ ?fuseaction=Page.ViewPage\&pageId=471 [Accessed 3 March 2021]. 